\title{
Predictive factors of success in selective laser trabeculoplasty (SLT) treatment
}

This article was published in the following Dove Press journal:

Clinical Ophthalmology

7 May 2011

Number of times this article has been viewed

\author{
Marcelo Ayala \\ Enping Chen \\ Glaucoma Department, St Erik \\ Eye Hospital, Karolinska Institutet, \\ Stockholm, Sweden
}

\begin{abstract}
Purpose: Glaucoma is a progressive optic neuropathy that may lead to blindness. Reducing intraocular pressure (IOP) is the only known treatment to slow progression in glaucoma. IOP can be reduced by pharmaceutical treatment, laser and surgery. The aim of the present study was to assess predictive factors of success after selective laser trabeculoplasty (SLT) treatment.

Methods: We used a retrospective chart review of eyes that underwent SLT between January 1, 2005 and December 31, 2005. The dependent variable was time to failure after SLT treatment. Failure after SLT was defined as any changes in the medical treatment, and/or a new SLT treatment was performed and/or the patient was sent for surgery. All patients were treated with $90^{\circ} \mathrm{SLT}$. A multivariate regression analysis was performed to assess correlation between time to failure after SLT and age, gender, IOP before treatment, number of medications used, SLT number, amount of spots, laser energy used, grade of angle, pigmentation and diagnosis.

Results: 120 eyes of 120 patients were identified. The average time to failure after SLT was 18 months. The predictive factors identified were: age, IOP before SLT and dose.

Conclusion: Predictive factors identified in our study were high baseline IOP, age and amount of laser energy used. Our study confirms previous results about baseline IOP as a predictive factor.
\end{abstract}

Keywords: glaucoma, laser, predictive factors, time to failure

\section{Introduction}

Glaucoma is a progressive neuropathy localized in the optic nerve and it is among the leading causes of blindness worldwide. ${ }^{1}$ Reducing intraocular pressure (IOP) seems to be the only treatment that slows progression in glaucoma. There are several methods to reduce IOP: pharmaceutical treatment, laser treatment and surgery. In the Glaucoma Laser Trial Follow-up study, after 7 years of follow-up, patients who had undergone argon laser trabeculoplasty (ALT) had lower IOP than patients on pharmaceutical treatment. ${ }^{2,3}$ However, in selective laser trabeculoplasty (SLT) there is still not sufficient evidence to determine the effectiveness of SLT compared to medication. SLT appears to be less costly than current pharmaceutical treatment. ${ }^{4}$

ALT was introduced about 35 years ago and involves the use of a blue/green argon laser (major wavelength peaks at $488 \mathrm{~nm}$ and $514 \mathrm{~nm}$ ) to treat the outer part of the trabecular meshwork and thereby improve aqueous outflow and thus reduce IOP. SLT uses a 532-nm frequency-double q-switched nd:YAG laser that delivers a low-energy, large spot, very brief pulse to selectively target cells of the trabecular meshwork. This "gentler" laser application is thought to stimulate the pigmented trabecular meshwork cells and thus facilitate improved aqueous outflow. The exact mechanism of action for
Correspondence: Marcelo Ayala

St Erik Eye Hospital, Polhemsgatan 50,

SE-I 1282 Stockholm, Sweden

Tel +4686723507

Fax +4686723325

Email marcelo.ayala@sankterik.se 
reducing the IOP is not known..$^{5}$ As SLT is a relatively new treatment alternative it is important for clinicians to assess the probability of successful IOP reduction. Assessment of predictive factors may determine which patients have a greater probability of achieving acceptable IOP reduction. The aim of the present study was to identify predictive factors of success in SLT treatment.

\section{Materials and methods}

This was a retrospective chart review of patients treated from January 1, 2005 till December 31, 2005. Inclusion criteria were open-angle glaucoma (primary open angle, pseudoexfoliation or pigmentary glaucoma) and ocular hypertensive (OHT) patients, older than 18 years, who were uncontrolled on pharmaceutical therapy and who had been given SLT treatment. Patients who could not be followed for at least 4 years were excluded.

Data recorded from each patient included age, sex, type of glaucoma, glaucoma medications and the SLT protocol (number of spots and laser power settings). The IOP values before and after SLT were also registered. All patients continued with the same pharmaceutical treatment after SLT.

The SLT protocol consisted of treatment that was performed in $90^{\circ}$ with the SLT Solo laser (Ellex, Adelaide, Australia) using between 25 and 30 spots applied to the trabecular meshwork. The energy level ranged from 0.6 to $1.0 \mathrm{~mJ}$. All patients were treated by the same physician (E.C.). Apraclonidine was instilled once after SLT treatment. Follow-up IOP measurements were obtained at least 1, 6, 12, 24 and 48 months after SLT treatment. The authors followed the Tenets of the Declaration of Helsinki.

The main outcome variable analyzed was the time to failure after SLT treatment. Failure after SLT was defined as any one or more of the following: change in the pharmaceutical treatment; performance of a further SLT treatment; the patient being sent for surgery.

When two eyes of the same patient were treated, one eye was chosen at random for analysis. All data were entered into a database. Multivariate regression analysis was performed to see significant correlations between the variables $(P=0.05)$. The general purpose of multiple regression analysis is to learn more about the relationship between several independent or predictor variables and a dependent or criterion variable. Independent variables: age, gender, IOP before treatment, number of medications used, SLT number, amount of spots, energy used, grade of angle (0-4), pigmentation (0-3) and diagnosis. Dependent variable: time to failure after SLT treatment. Statistical software: STATA (Statacorp, College Station, TX).

\section{Results}

In all, 120 eyes of 120 patients were identified during the defined time period. The baseline characteristics of the sample are given in Table 1.

The multivariate analysis showed a significant negative correlation between age and time to failure $(P=0.015)$. With increasing age the time to failure was shortened. The IOP before SLT treatment also showed a significant negative correlation with time to failure after SLT $(P \leq 0.001)$, meaning that with higher IOP before treatment, time to failure was shortened.

Laser energy used and time to failure showed a slight significant positive correlation $(P=0.047)$. With increasing energy, there was a longer time to failure after SLT. See Table 2 .

\section{Discussion}

Selective laser trabeculoplasty is a commonly accepted therapy for lowering IOP. The present study aims to answer the question of factors that can predict success of SLT over a longer period of time (4 years). Predictive factors have been reported by Gracner et $\mathrm{al}^{6}$ showing a negative correlation between successful SLT and the grade of trabecular meshwork pigmentation and diabetes. The authors did not find any significant correlations between successful SLT and baseline IOP, age, sex, hypertension, family history of glaucoma, previous anterior segment surgery, laser energy used and local antiglaucoma therapy. This study found that SLT efficacy is positively associated with IOP elevation before laser treatment. This is consistent with Hodge et $\mathrm{al}^{7}$

Table I Baseline characteristics of the subjects included in the study

\begin{tabular}{ll}
\hline Characteristic & \\
Age (SD) & $76.5($ I I.8) years \\
Gender & $75 \%$ women \\
IOP before SLT (mm Hg) (SD) & $24.7(4.6)$ \\
Number of SLT procedures undergone: & \\
SLT I (\%) & $74(62)$ \\
SLT 2 (\%) & $38(32)$ \\
SLT 3 (\%) & $5(4)$ \\
SLT 4 (\%) & $3(2)$ \\
Average number of spots per eye (SD) & $26.9(4.8)$ \\
Average dose per eye (mJ) (SD) & $0.88(0.1 \mathrm{I})$ \\
Average anterior chamber (0-4) (SD) & $3.8(0.49)$ \\
Average pigmentation (0-3) (SD) & $0.77(0.66)$ \\
Diagnosis: & \\
Exfoliative glaucoma (\%) & $73(6 \mathrm{I})$ \\
Primary open angle glaucoma (\%) & $34(28)$ \\
Ocular hypertension (\%) & $9(7.5)$ \\
\hline
\end{tabular}

Abbreviations: SD, standard deviation; SLT, selective laser trabeculoplasty. 
Table 2 Multivariate regression analysis: time to failure dependent variable

\begin{tabular}{lll}
\hline Variables & Test value (T) & Probability $(\boldsymbol{P})$ \\
\hline Age & 2.48 & $0.015\left(^{*}\right)$ \\
Gender & 0.57 & 0.571 \\
SLT number & 0.59 & 0.557 \\
Number of spots & $\mathrm{I}$ & 0.318 \\
Laser energy & 2.01 & $0.047\left(^{*}\right)$ \\
Grade of angle (0-IV) & 0.06 & 0.95 \\
Pigmentation (0-III) & 0.41 & 0.686 \\
IOP before SLT & 3.75 & $<0.001\left(^{*}\right)$ \\
Diagnose & 0.56 & 0.57 \\
Number of medications & 0.7 & 0.866 \\
\hline
\end{tabular}

Note: Significant correlations are marked $(*)$.

Abbreviations: SLT, selective laser trabeculoplasty; IOP, intraocular pressure.

who reported that SLT success was significantly predicted by baseline IOP but not by age, sex, other glaucoma risk factors, type of open angle glaucoma or by degree of trabecular meshwork pigmentation. Also this study is consistent with Mao et $\mathrm{l}^{8}$ who reported a positive association between laser efficacy and IOP before SLT treatment. Our results are also in line with the results presented by George et $\mathrm{al}^{9}$ who found that baseline IOP was the only preoperative predictive factor for response to ALT and non overlapping SLT.

We found a significant correlation between successful SLT and age, baseline IOP and amount of laser energy delivered. Comparisons among studies are always difficult to perform due to different populations studied, different time periods, how failure was defined, etc. The fact that Gracner et $\mathrm{al}^{6}$ did not find a significant correlation between baseline IOP and success might be due to different levels of IOP in the patients included. In our study the mean level of baseline IOP was $24.7 \mathrm{mmHg}$ meanwhile Gracner et al ${ }^{6}$ included patients with IOP $22.5 \mathrm{mmHg}$. Mao et al ${ }^{8}$ found a positive correlation between IOP reduction and IOP before SLT treatment including patients with a baseline IOP of $26 \mathrm{~mm} \mathrm{Hg}$. Lower baseline pressures have been associated with a reduced pressure-lowering effect. ${ }^{10}$

A significant negative correlation between age and time to failure $(P=0.015)$ was found in this study. This means that with increasing age the time to failure was shortened. The mean age of the included patients in our study was quite high (76.5 years). SLT's IOP reduction mechanisms are still unknown but it has been postulated that activation of prostaglandins can have certain effects. ${ }^{11}$ Probably chemical factors are reduced due to increased age, thus shortening the time IOP reduction is maintained after SLT. Another possible explanation could be the severity of the existing glaucoma. Older patients tend to have more advanced glaucoma, so the physicians who examined those patients after SLT treatment may not have been satisfied with the IOP reduction gained and changed the treatment, thus increasing the number of cases classified as "failure." In comparable studies, younger patients were included. Gracner et $\mathrm{al}^{6}$ included patients that were 70.3 years meanwhile Hodge et $\mathrm{al}^{7}$ included patients that were 69.08 years. Mao et $\mathrm{al}^{8}$ included patients that were 63 years. None of these studies found a significant correlation between age and success after SLT treatment.

The amount of laser energy delivered during SLT treatment was identified as a predictive factor in our study. Laser energy used and time to failure showed a slight significant positive correlation $(P=0.047)$ : with increasing energy, there was a longer time to failure after SLT. Gracner et al, ${ }^{6}$ Hodge et $\mathrm{al}^{7}$ and Mao et $\mathrm{al}^{8}$ did not find any correlation between laser energy used and success after SLT treatment. The average total laser energy used by Gracner et $\mathrm{al}^{6}$ was around $40 \mathrm{~mJ}$. Hodge et $\mathrm{al}^{7}$ used an energy around $44 \mathrm{~mJ}$ while Mao et $\mathrm{al}^{8}$ reported an energy of $41 \mathrm{~mJ}$. The average total energy used in our study was $23.67 \mathrm{~mJ}$. A particular point to be considered is that the laser protocol used in our study treated just $90^{\circ}$ of the trabecular meshwork making our results difficult to compare with previous published results. It is possible to speculate that SLT treatment in $180^{\circ}$ would decrease the failure rates.

Our study is limited by its retrospective design. One issue to be considered is selection bias. All patients were treated at a tertiary referral center where the patient population tends to have more advanced glaucoma. Severity of glaucoma may have been a confounding factor; however, this was not directly evaluated in this study. Ethnicity was not recorded in the medical journals of the patients included in the study, therefore ethnicity could not be evaluated in the study. It is reasonable to assume that the majority of the patients were Caucasians. Another possible selection bias is the high percentage of pseudoexfoliative glaucoma patients included in the study (61\%). Exfoliation is a common problem in Sweden. We did not find a correlation between different diagnosis and time to failure after SLT treatment. These results are consistent with Gracner ${ }^{12}$ who found no difference in SLT results comparing capsular glaucoma and primary open-angle glaucoma. Further prospective clinical cohort studies are needed to confirm these results.

Predictive factors identified in our study were high baseline IOP, age and amount of laser energy used. Our study confirms previous results about baseline IOP as a predictive factor. IOP before SLT treatment seems to be a predictive factor for success even when SLT treatment was delivered 
in $90^{\circ}$. As a general recommendation coming from the study it is possible to say that SLT treatment works well among patients with IOP around 24-26 $\mathrm{mmHg}$, while lower baseline pressures have been associated with a reduced pressurelowering effect. Further studies with longer follow-up and bigger sample sizes are needed.

\section{Disclosure}

This research was supported by grants from the Karolinska Institutet and the Loo and Hans Östermann Foundation.

\section{References}

1. Sommer A, Tielsch JM, Katz J, et al. Racial differences in the causespecific prevalence of blindness in east Baltimore. $N$ Engl $J$ Med. 1991;325(20):1412-1417.

2. The Glaucoma Laser Trial Research Group. The Glaucoma Laser Trial (GLT). 2. Results of argon laser trabeculoplasty versus topical medicines. Ophthalmology. 1990;97(11):1403-1413.

3. The Glaucoma Laser Trial Research Group. The Glaucoma Laser Trial (GLT) and glaucoma laser trial follow-up study: 7. Results. Am J Ophthalmol. 1995;120(6):718-731.

4. Lee R, Hutnik CM. Projected cost comparison of selective laser trabeculoplasty versus glaucoma medication in the Ontario Health Insurance Plan. Can J Ophthalmol. 2006;41(4):449-456.
5. Latina MA, Park C. Selective targeting of trabecular meshwork cells: in vitro studies of pulsed and CW laser interactions. Exp Eye Res. 1995;60(4):359-371.

6. Gracner T, Naji M, Hudovernik M, Gracner B, Pahor D. Predictive factors of successful selective laser trabeculoplasty in open-angle glaucoma. Klin Monbl Augenheilkd. 2007;224(12):922-926.

7. Hodge WG, Damji KF, Rock W, Buhrmann R, Bovell AM, Pan Y. Baseline IOP predicts selective laser trabeculoplasty success at 1 year post-treatment: results from a randomised clinical trial. Br JOphthalmol. 2005;89(9):1157-1160.

8. Mao AJ, Pan XJ, McIlraith I, Strasfeld M, Colev G, Hutnik C. Development of a prediction rule to estimate the probability of acceptable intraocular pressure reduction after selective laser trabeculoplasty in open-angle glaucoma and ocular hypertension. J Glaucoma. 2008;17(6):449-454.

9. George MK, Emerson JW, Cheema SA, et al. Evaluation of a modified protocol for selective laser trabeculoplasty. $J$ Glaucoma. 2008;17(3):197-202.

10. Song J, Lee PP, Epstein DL, et al. High failure rate associated with 180 degrees selective laser trabeculoplasty. J Glaucoma. 2005; 14(5):400-408.

11. Alvarado JA, Iguchi R, Juster R, Chen JA, Shifera AS. From the bedside to the bench and back again: predicting and improving the outcomes of SLT glaucoma therapy. Trans Am Ophthalmol Soc. 2009;107:167-181.

12. Gracner T. Intraocular pressure response of capsular glaucoma and primary open-angle glaucoma to selective Nd:YAG laser trabeculoplasty: a prospective, comparative clinical trial. Eur $J$ Ophthalmol. 2002;12(4):287-292.
Clinical Ophthalmology

\section{Publish your work in this journal}

Clinical Ophthalmology is an international, peer-reviewed journal covering all subspecialties within ophthalmology. Key topics include: Optometry; Visual science; Pharmacology and drug therapy in eye diseases; Basic Sciences; Primary and Secondary eye care; Patient Safety and Quality of Care Improvements. This journal is indexed on

Submit your manuscript here: http://www.dovepress.com/clinical-ophthalmology-journal

\section{Dovepress}

PubMed Central and CAS, and is the official journal of The Society of Clinical Ophthalmology (SCO). The manuscript management system is completely online and includes a very quick and fair peer-review system, which is all easy to use. Visit http://www.dovepress.com/ testimonials.php to read real quotes from published authors. 